\title{
Securing for Academic Generalists the Opportunities and the Recognition that They Deserve
}

\author{
Martin F. Shapiro, MD, PhD \\ Division of General Internal Medicine, Weill-Cornell Medical College, New York, NY, USA.
}

J Gen Intern Med 32(7):725-7

DOI: $10.1007 / \mathrm{s} 11606-017-4014-1$

() Society of General Internal Medicine 2017

$\mathrm{T}$ he proliferation of medical specialties and the exponential growth of Federal funding of basic science research coincided with the near extinction of generalist faculty from many medical schools after World War II. The renaissance of academic general medicine began in the 1970s, primarily in recognition of a need for ambulatory and inpatient general medicine teaching. Research programs grew around these clinical activities and included clinical epidemiology and decision-making, study of the clinical encounter, health services research and medical education. General pediatrics followed a similar trajectory. Family medicine grew as well, but with less emphasis on research, perhaps because the units were situated in departments without strong research traditions. Funding for generalist research has been challenging. ${ }^{1} \mathrm{NIH}$ support varies dramatically by institute. The National Center for Health Services Research (now AHRQ) has supported such work, but funding has been intermittent, regularly threatened by congress and heavily influenced by political considerations. The Affordable Care Act opened important new funding streams, notably PCORI, but its future, with the prospect of ACA repeal, is highly questionable.

Many GIM academic units have experienced explosive growth in the numbers of individuals devoting almost full time to provision of patient care as health systems vie for a greater market share. Some now include hundreds of generalists involved in inpatient and/or outpatient care, employed by their medical schools, often with academic appointments. While most do some teaching, institutions will be hard-pressed to keep pace, in terms of opportunities for substantial teaching and creative activity involvement, with these expanding numbers of clinicians.

In this context, the paper by Blazey-Martin and her colleagues ${ }^{2}$ provides valuable insights about experiences with academic promotion of an earlier generation of generalists. They studied a cohort of academicians who began their careers on average in the 1980s, sampling equal numbers of generalists, medical specialists, surgeons and basic scientists, and assessed time commitments in 1995, productivity in terms of publications, and whether or not they achieved the rank of full

Published online March 10, 2017 professor. Basic scientists were different from the other groups, devoting the majority of their time to research and having more federal grants, more publications in peerreviewed journals and greater impact of their publications, and they were more likely to have achieved the rank of professor. Among the three groups of clinical faculty, generalists were at least as likely to obtain federal grant support, but had fewer publications and less impact of their publications, and they were less likely to be promoted. Controlling for numbers of publications explained the difference in promotion rates across these groups. Generalists devoted $18 \%$ of work time to research compared to 23 and $24 \%$ for medical specialists and surgeons. Their lifetime number of publications was also about three-fourths that of the other two groups.

The authors judge that academic medicine "over-weights research and undervalues the work of generalists" in clinical care and teaching and suggest criteria be adjusted to "quantify and value" teaching and clinical contributions, while "ensuring that adequate time is protected for scholarly work."

Medical school faculty who do valuable work should have that value recognized. ${ }^{3}$ The task is not a simple one, though. Many medical schools have distinct academic series with different expectations for promotion. The data presented suggest that the series, on average, are not titrated to achieve comparable outcomes. However, the data do not distinguish between faculty in different academic series. When generalist clinician-scientists are hired, some are given up to $80 \%$ time to pursue scholarly work, which is comparable to clinicianscientists in other disciplines. That kind of appointment requires considerable investment by a division or department; not all are in a position to or are not prepared to offer that kind of deal. Accordingly, other aspiring clinician-scientists are given much smaller amounts of time for scholarship and are told that they can buy out clinical time if they get extramural support. Of course, getting such support is very difficult without the time to do the work. Furthermore, unlike some procedural fields in which physicians can work 2 or 3 half days a week clinically and cover substantial additional time that they can apply to research, generalists mostly cannot even cover with net clinical revenue the time spent generating it.

This sort of structural problem only can be solved by institutional subsidy (which can be justified by the business generalists bring to the hospital and the specialties). ${ }^{4}$ Talented young faculty members may be fortunate enough to obtain career development awards that pay $\$ 75,000$ to $\$ 100,000$ per 
year of salary, for which they are required to spend $75 \%$ of their time doing research or study related to the award. Even efficient clinical work in the remaining time will not result in competitive salaries. After career development awards expire, transition to " $R$ " investigator-initiated research grants is difficult. Most do not succeed the first time, and many never do get these grants, for which success rates have been in the 10 to $20 \%$ range in recent years. For those who do get one, they are not done. Assuming that they budget 50\% time (which is a lot) at the NIH cap, which is less than $\$ 190,000$, how do they cover the rest of their salary? The occasional talented investigator can land two such awards, but that is quite unusual. They might participate on others' grants and perhaps approach the cap or get funding from foundations and other sources. It is a tough life. As a very successful colleague of mine said of funding, "some years, I dangle by my fingernails. Other years, I have all fingers firmly planted on the ledge."

Clinician-educators also require institutional subsidies. In the 1980s, many saw patients perhaps five times a week and had other funded responsibilities. More recently, with the pressure to capture more "covered lives" (what we used to call people), many newer recruits see patients 8 or 9 half days per week, an economic and practice model that seems to work for their departments. Does it work for these physicians? If they aspire to be practicing docs doing a limited amount of teaching and receiving some institutional salary support, it well may, and they might not care about their academic titles. If they aspire to doing something creative, it can be very difficult. Even without that aspiration, if their institution requires creative products for promotion, and if compensation or retirement benefits are tied to academic rank, they may care a great deal about academic advancement.

Not everyone who can contribute to a medical school's programs is prepared or motivated to write scholarly papers. ${ }^{5}$ UCLA created an online publication in which clinicianeducators can publish review articles or case reports. This type of publication is considered to be acceptable evidence of creativity. However, many busy clinicians do not approach this expectation with much joy and require intensive mentorship to complete the task. There is little doubt that these clinician-educators have great value to their institutions. We need other ways to document their accomplishments for purposes of promotion. Promotion criteria that recognize other forms of creativity, such as design of innovative educational programs, have been adopted in some universities. ${ }^{6}$ Still, it is hard to imagine a creative or innovative educational program for which every faculty member can take genuine credit in divisions with 200 or more clinicians!

Clinician-educators who play administrative or more substantial teaching roles have less time committed to patient care, but may not have very much time available for research. Even more critically, most have not had research fellowships, making it difficult for them to design and execute studies that would pass muster at peer-reviewed journals or to write research grants. If they run great residency programs, overcome myriad barriers to making clinic a meaningful experience for residents, and help to design and lead exciting behavioral medicine or evidence-based medicine programs that profoundly affect the outlooks of students, shouldn't that be enough for us? For the clinician-educators who do not run programs, it is entirely legitimate to consider contributions to curricula, teaching programs, administration of clinical services, or development of clinical pathways, or placing lectures or teaching files on resident websites as legitimate creative contributions. Changing promotions policies to recognize such contributions ${ }^{7}$ is not an easy road. Universities replete with professors who earn far less than physicians are predictably resistant to such changes.

The primary care specialties need to go all in when recruiting clinician-investigators, with financial support, start-up funds, protected time comparable to scientists in other disciplines and no cliff to fall from if there is even a substantial funding gap, especially in the early years, when the individual has been genuinely productive. Generalist clinician-scientists cannot be expected to subsidize research time with clinical work. In California, even a starting salary of $\$ 160,000$ is becoming uncompetitive. Assuming a 3-year guarantee at that level, with an additional onethird for benefits, and additional $\$ 100,000$ in start-up funds and administrative support, and an offset of $\$ 30,000$ per year in clinical revenue, this requires a commitment of $\$ 640,000$ or more up front (only potentially offset by extramural funding).

Many departments have been slow to grasp what is required for successful generalist scholarship as the following anecdotes demonstrate: The chair of medicine at one institution complained to me that his generalists were only seeing patients 7 half days a week and still not doing any research. He did not consider that clinical work spilled over into "free" time. Another school sought consultation on how to build an academic generalist division. They lacked key basic (social science) disciplines. I suggested hiring some social scientists as well as generalist researchers with multi-year guarantees and substantial ongoing subsidies for those who succeed, as well as subsidies for clinician-educators. The dean told me that that would take an endowment of about \$25 million, and how could he possibly commit to something of that magnitude, since it was as much as he was spending on a new animal house (no, not the movie)! A former leader of the AAMC told a group of generalist researchers that it was much easier for generalists to maintain research programs because basic scientists need to be in the lab all day, whereas generalists can sit down at their computers for an hour or two after clinic and do their research at that time.

Generalist academic units lack the resources to commit to guarantees of the size outlined above. Research by generalists, just as by basic scientists, requires institutional investment. Readers of this journal understand that generalist scholarship provides value to society and to academic institutions by improving educational programs, efficiency and quality of care, access and outcomes. ${ }^{8}$ Still, I am reluctant to suggest that we make our case based on institutional utility. Basic scientists who study molecular genetics and myocyte physiology don't need to. 
How can we help generalists succeed academically at the same rate as other specialties? First, educate medical school and hospital leadership about what we do and its value to society and to the institution. ${ }^{4,8}$ Second, convince them to invest in generalist research, teaching and clinical programs. Third, inform them about what generalist faculty need to succeed, in terms of institutional resources and time commitment, and make sure that recruitment packages reflect that. Fourth, secure generalist representation (including clinician-educators) on departmental promotion committees to speak to the value and complexity of generalist scholarship, and fight to change institutional policies and attitudes of promotion committee leadership, ${ }^{9}$ to make sure that individuals seeing patients $80 \%$ of the time are not evaluated with the same metric as those primarily doing research. Finally, learn to what each faculty member aspires. Then, work with them and others to help them achieve that. If they value promotion, create institutional structures and mentorship systems that will allow them to be promoted, even if "creative contribution" has a different meaning from what it is for an $80 \%$-time researcher.

Taking our cue from Blazey-Martin, we should monitor promotions processes within institutions, generate expectations that are consistent with details of faculty members' time commitments, identify any inequity across clinical specialties in promotion actions and make the case for broadening institutional definitions of creativity.
Corresponding Author: Martin F. Shapiro, MD, PhD; Division of General Internal MedicineWeill-Cornell Medical College, New York, NY, USA (e-mail: mfs2004@med.cornell.edu).

\section{Compliance with Ethical Standards:}

Conflict of Interest: The author has no conflicts of interest with this article.

\section{REFERENCES}

1. Shapiro MF, Larson EB. Funding for medical care research. J Gen Intern Med. 1987;2:113-8.

2. Blazey-Martin D, Carr PL, Terrin N, et al. Lower rates of promotion of generalists in academic medicine: a follow up to the National Faculty Survey. J Gen Intern Med. 2017. doi:10.1007/s11606-016-3961-2.

3. Levinson W, Rubenstein A. Mission critical-integrating clinicianeducators into academic medical centers. N Engl J Med. 1999;341:840-3.

4. 2016 Physician Inpatient/Outpatient Revenue Survey. Available at: https://www.merritthawkins.com/uploadedFiles/MerrittHawkins/Surveys/Merritt_Hawkins-2016_RevSurvey.pdf. Accessed 31 Jan 2017.

5. Lucey CR. Promotion of clinician-educators. J Gen Intern Med. 2003; 18:768-9.

6. UCLA Academic Personnel Office. Appendix 5: instruction to review \& appraisal committees. Available at: https://www.apo.ucla.edu/policiesforms/the-call/appendices/appendix-5-instructions-to-review-appraisalcommittees. Accessed 31 Jan 2017.

7. UCLA Academic Personnel Office. Appendix 8: instructions to review and appraisal committees for the health sciences clinical professor series. Available at: https://www.apo.ucla.edu/policies-forms/the-call/appendices/appendix-8-instructions-to-review-and-appraisal-committees-for-thehealth-sciences-clinical-professor-sereis/\#V.C. Accessed 31 Jan 2017.

8. Starfield B, Shi L, Macinko J. Contribution of primary care to health systems and health. Milbank Q. 2005;83:457-502.

9. Atasoylu AA, Wright SM, Beasley BW, et al. Promotion criteria for clinician-educators. J Gen Intern Med. 2003;18:711-6. 